\title{
Seed Storage Potential Assessment in Onion (Allium cepa L. cv. CO (On) 5) through Forced Ageing
}

\author{
S. Sivasakthi* and J. Renugadevi \\ Department of Seed Science and Technology, Tamil Nadu Agricultural University, \\ Coimbatore - 641 003, Tamil Nadu, India \\ *Corresponding author
}

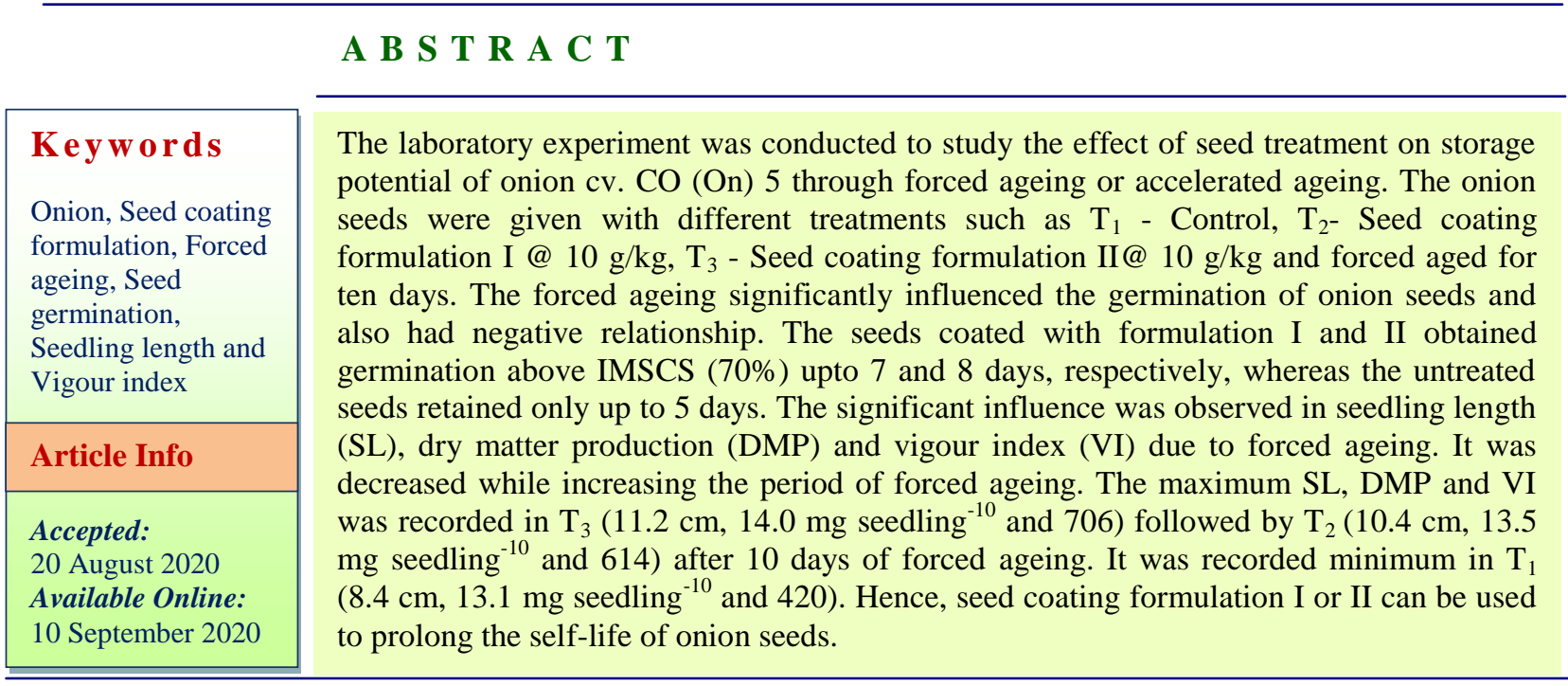

\section{Introduction}

Many of our crops are reproduced through seeds, and throughout the world large quantities of seeds are produced, stored and transported. All seeds undergo aging process during long-term storage which leads to deterioration in seed quality. However, the rate of seed deterioration is varying among various plant species (Merritt et al., 2003). Onion (Allium cepa L.) seeds lose vigour and viability at faster rates than seeds of most other vegetables (Choudhari and Basu, 1988).
Seed ageing during storage may cause retardation of field establishment and may eventually result in seedling abnormalities or even failure of emergence.

Seed viability is a matter of great concern and measures to maintain germination efficiency of stored seeds have significant economic implications. A range of pre-harvest, harvest and post-harvest conditions affect seed viability (Basu, 1995). Many factors contribute to seed ageing. These include genetics, mechanical damage, relative 
humidity and temperature of the storage environment, seed water content, presence of micro flora, seed maturity etc. The rate of loss of seed viability is mainly a function of temperature and seed moisture content (McDonald, 1999, 2004). During ageing, seed viability and vigour decreases. Furthermore, the losses of viability and vigour in seeds differ with species and cultivars. Predicting the longevity of stored seeds is therefore highly relevant from an economic and social point of view.

Storage experiments have been performed to estimate the longevity of seed lots in a large number of species. But, it takes long period of time to predict the storability of seeds. So, forced ageing or accelerated ageing test used to predict the storability of seeds in a short period of time. Most often this involves storage of the seeds at an elevated moisture and temperature. When the seeds are stored at an elevated temperature and the relative humidity $(\mathrm{RH})$ of the atmosphere surrounding the seeds is 100 per cent, the test is called as forced ageing or accelerated ageing. Accelerated ageing test frequently used as indicator for seed longevity under conventional storage condition.

Deloucheand Baskin (1973) reported that accelerated ageing study technique could be effectively used for evaluating the seedling vigour and also for knowing relative storability of the seed. In the present study seeds were given with different treatments and subjected to forced ageing for ten days to know the storability.

\section{Materials and Methods}

The laboratory experiment was undertaken at Department of Seed Science and Technology, Tamil Nadu Agricultural University, Coimbatore, Tamil Nadu, India during 201718. Onion seeds (Allium cepa L. cv. CO (On)
5) were obtained from Department of Vegetable Crops, Horticultural College and Research Institute, Tamil Nadu Agricultural University, Coimbatore, Tamil Nadu, India. The onion seeds were given with different treatments such as $\mathrm{T}_{1^{-}}$- Control, $\mathrm{T}_{2}$ - Seed coating formulation I (consist of polymer-800 $\mathrm{g}$, pigment-200 g, gibberellic acid-5 $\mathrm{mg}$ and carboxyl methyl cellulose-10 g) @ $10 \mathrm{~g} / \mathrm{kg}$ and $\mathrm{T}_{3}$ - Seed coating formulation II (consist of polymer-800g, pigment-200g, brassinosteroid $-0.1 \mu \mathrm{l}$ and carboxyl methyl cellulose $-10 \mathrm{~g}$ ) @ $10 \mathrm{~g} / \mathrm{kg}$ of seeds. A $20 \mathrm{~g}$ seeds from each treatment was forced aged at $100 \% \mathrm{RH}$ and $40^{\circ} \mathrm{C}$ for ten days. For this, 20 $\mathrm{g}$ seeds were divided in to 10 parts (2 $\mathrm{g}$ each) and packed in small perforated butter paper covers and arranged loosely inside desiccators. To maintain $100 \% \mathrm{RH}, 40 \mathrm{ml}$ of water was taken at the bottom of the desiccator and the lid was closely tightened. For maintaining $40^{\circ} \mathrm{C}$ temperature, the desiccator with seed packets was kept inside a B.O.D incubator set at $40^{\circ} \mathrm{C}$. Daily one seed packet was drawn up to ten days and the seeds were evaluated for the seed quality parameters.

\section{Design of the experiment}

The laboratory experiment was conducted in the completely randomized block design with two factorial concepts and replicated four times.

\section{Observations}

\section{Seed germination (\%) (ISTA, 2013)}

The germination test was carried out as per the procedure prescribed by ISTA with four replicates of 100 seeds in paper medium. The test conditions were $25 \pm 2^{\circ} \mathrm{C}$ and $95 \pm 5 \%$ RH maintained in a germination room illuminated with fluorescent light. After twelve days, the seedlings were evaluated and 
the normal seedlings with "knee bent" were counted and expressed as germination percentage.

\section{Root length (cm)}

Ten normal seedlings from the standard germination test were randomly selected and the root length was measured from the collar region to the tip of the primary root and the average expressed in centimeter.

\section{Shoot length $(\mathrm{cm})$}

Ten normal seedlings were randomly selected from the standard germination test and the length from the collar region to the tip of the shoot was measured and the average expressed in centimeter.

\section{Dry matter production ( $\mathrm{mg}$ seedlings ${ }^{-10}$ ) (ISTA, 2013)}

The seedlings used for growth measurement were placed in a paper cover and dried in shade for $24 \mathrm{~h}$ and then kept in an oven maintained at $85 \pm 2{ }^{\circ} \mathrm{C}$ for $24 \mathrm{~h}$. The dried seedlings were removed from the hot air oven and cooled in the desiccators over silica gel. Dry weight was recorded and the mean values were expressed in $\mathrm{mg}$ seedlings ${ }^{-10}$.

\section{Vigour index (Abdul-Baki and Anderson,} 1973)

Vigour index values were computed using the following formula and the mean values were expressed in whole number.

Vigour index $=$ Germination $(\%) \times$ Total seedling length $(\mathrm{cm})$

\section{Statistical analysis}

The data collected from the experiment was analyzed statistically adopting the procedure described by Panse and Sukhatme (1985). Wherever necessary, the per cent values were transformed to angular (Arc-sine) values before analysis. The critical differences (CD) were calculated at 5 per cent $(\mathrm{P}=0.05)$ probability level. If the $\mathrm{F}$ test is nonsignificant it was indicated by the letters NS.

\section{Results and Discussion}

The forced ageing technique is commonly used, through which changes in the seed at the cellular level during long term storage can be stimulated within a comparatively short period of time by exposing seeds to increased temperature $\left(40-45^{\circ} \mathrm{C}\right)$ and a high relative humidity $(100 \%)$.

The forced ageing significantly influenced the germination of onion seeds and also had negative relationship. The seeds coated with seed coating formulation I (SCF-I) and seed coating formulation II (SCF-II) obtained germination above IMSCS (70\%) upto 7 and 8 days, respectively, whereas the untreated seeds retained only up to 5 days. The maximum germinability of 63 per cent was maintained by SCF-II which was higher than SCF-I (59) and control (50) at 10 days after forced ageing (Table 1) (Figure $1 \& 2$ ). Failure of aged seeds to germinate may be attributed to lipid peroxidation, mitochondrial disfunction and less ATP production (Basra et al., 1994). Accelerated ageing adversely affects the seed viability and vigour in pea seeds (Khan et al., 2003). Seed germinability maintenance effect of SCF- I and II may be due to the hormones present in that. SCF-II contains brassinosteroid (BR) and SCF- I contains gibberellic acid $\left(\mathrm{GA}_{3}\right)$, it may enhance and maintains the seed germination during forced ageing. Brassinosteroid application has been reported to enhance germination in several crops (Takeuchi et al., 1995 in parasitic angiosperms; Steber and McCourt, 2001 in Arabidopsis; Leubner- 
Metzger, 2001 in tobacco). Pretreatment with brassinolide has been found to stimulate the

germination and seedling emergence of aged rice seeds (Yamaguchi et al., 1987).

Table.1 Effect of seed treatment and forced ageing on seed germination

\begin{tabular}{|c|c|c|c|c|}
\hline \multirow{2}{*}{$\begin{array}{c}\text { Days after forced } \\
\text { ageing }\end{array}$} & \multicolumn{4}{|c|}{ Germination (\%) } \\
\hline Fresh seed & $90(71.57)$ & $92(73.57)$ & $94(75.82)$ & $92(73.57)$ \\
\hline $\mathbf{1}$ & $87(68.87)$ & $90(71.57)$ & $91(72.54)$ & $89(70.63)$ \\
\hline $\mathbf{2}$ & $84(66.42)$ & $86(68.02)$ & $88(69.73)$ & $86(68.02)$ \\
\hline $\mathbf{3}$ & $80(63.44)$ & $83(65.65)$ & $85(67.22)$ & $83(65.65)$ \\
\hline $\mathbf{4}$ & $77(61.74)$ & $81(64.16)$ & $83(65.65)$ & $80(63.44)$ \\
\hline $\mathbf{5}$ & $72(58.05)$ & $78(62.03)$ & $80(63.44)$ & $77(61.34)$ \\
\hline $\mathbf{6}$ & $68(55.55)$ & $75(60.00)$ & $78(62.02)$ & $74(59.34)$ \\
\hline $\mathbf{7}$ & $64(53.13)$ & $72(58.05)$ & $75(60.00)$ & $70(56.79)$ \\
\hline $\mathbf{8}$ & $59(50.19)$ & $68(55.55)$ & $72(58.05)$ & $66(54.33)$ \\
\hline $\mathbf{9}$ & $54(47.30)$ & $63(52.54)$ & $67(54.94)$ & $61(51.36)$ \\
\hline $\mathbf{1 0}$ & $50(45.00)$ & $59(50.19)$ & $63(52.54)$ & $57(49.03)$ \\
\hline Mean & $71(57.42)$ & $77(61.34)$ & $80(63.44)$ & $76(60.67)$ \\
\hline & FA & T & & FA X T \\
\hline SEd & 2.692 & 1.406 & & \multicolumn{2}{|c|}{ NS } \\
\hline CD(0.05) & 5.374 & 2.806 & & \\
\hline
\end{tabular}

Note: Figures in parenthesis indicate arcsine values

Fresh seed indicates seeds before forced ageing; FA- Forced ageing; T- Treatment; FA X T- Interaction between forced ageing and treatment; NS- Non-significant at 5 per cent $(\mathrm{P}=0.05)$ probability level

Table.2 Effect of seed treatment and forced ageing on seedling shoot length and root length

\begin{tabular}{|c|c|c|c|c|c|c|c|c|}
\hline \multirow{2}{*}{$\begin{array}{l}\text { Days after } \\
\text { forced ageing }\end{array}$} & \multicolumn{4}{|c|}{ Shoot length $(\mathrm{cm})$} & \multicolumn{4}{|c|}{ Root length $(\mathrm{cm})$} \\
\hline & $\mathrm{T}_{1}$ & $\mathrm{~T}_{2}$ & $\mathrm{~T}_{3}$ & Mean & $\mathrm{T}_{1}$ & $\mathrm{~T}_{2}$ & $\mathrm{~T}_{3}$ & Mean \\
\hline Fresh seed & 9.1 & 9.4 & 9.8 & 9.4 & 5.9 & 6.7 & 7.1 & 6.6 \\
\hline 1 & 8.5 & 8.9 & 9.3 & 8.9 & 5.6 & 6.4 & 6.9 & 6.3 \\
\hline 2 & 8.1 & 8.8 & 9.2 & 8.7 & 5.2 & 6.0 & 6.7 & 6.0 \\
\hline 3 & 7.6 & 8.6 & 9.0 & 8.4 & 4.9 & 5.8 & 6.5 & 5.7 \\
\hline 4 & 7.4 & 8.5 & 8.8 & 8.2 & 4.7 & 5.5 & 6.2 & 5.5 \\
\hline 5 & 7.1 & 8.2 & 8.5 & 7.9 & 4.3 & 5.1 & 5.9 & 5.1 \\
\hline 6 & 6.7 & 8.0 & 8.3 & 7.7 & 4.0 & 4.8 & 5.5 & 4.8 \\
\hline 7 & 6.4 & 7.7 & 8.0 & 7.4 & 3.8 & 4.6 & 5.2 & 4.5 \\
\hline 8 & 6.0 & 7.3 & 7.7 & 7.0 & 3.6 & 4.4 & 4.9 & 4.3 \\
\hline 9 & 5.7 & 7.0 & 7.3 & 6.7 & 3.3 & 4.1 & 4.6 & 4.0 \\
\hline 10 & 5.3 & 6.6 & 6.9 & 6.3 & 3.1 & 3.8 & 4.3 & 3.7 \\
\hline \multirow{2}{*}{ Mean } & 7.1 & 8.1 & 8.4 & 7.9 & 4.4 & 5.2 & 5.8 & 5.1 \\
\hline & FA & $\mathrm{T}$ & \multicolumn{2}{|c|}{ FA X T } & & FA & $\mathrm{T}$ & FA X T \\
\hline SEd & 0.112 & 0.058 & \multicolumn{2}{|c|}{0.194} & SEd & 0.069 & 0.036 & 0.119 \\
\hline $\mathrm{CD}(0.05)$ & 0.223 & 0.117 & \multicolumn{2}{|c|}{0.386} & $\mathrm{CD}(0.05)$ & 0.138 & 0.072 & NS \\
\hline
\end{tabular}


Table.3 Effect of seed treatment and forced ageing on seedling dry matter production and vigour index

\begin{tabular}{|c|c|c|c|c|c|c|c|c|}
\hline \multirow[t]{2}{*}{$\begin{array}{l}\text { Days after } \\
\text { forced ageing }\end{array}$} & \multicolumn{4}{|c|}{ Dry matter production (mg seedling- } & \multicolumn{4}{|c|}{ Vigour index } \\
\hline & $\mathbf{T}_{1}$ & $\mathbf{T}_{2}$ & $\mathbf{T}_{\mathbf{3}}$ & Mean & $\mathbf{T}_{1}$ & $\mathbf{T}_{2}$ & $\mathbf{T}_{\mathbf{3}}$ & Mean \\
\hline Fresh seed & 16.1 & 16.4 & 16.6 & 16.4 & 1350 & 1481 & 1589 & 1473 \\
\hline 1 & 15.8 & 16.0 & 16.3 & 16.0 & 1227 & 1377 & 1474 & 1359 \\
\hline 2 & 15.4 & 15.6 & 16.0 & 15.7 & 1117 & 1273 & 1399 & 1263 \\
\hline 3 & 15.0 & 15.2 & 15.8 & 15.3 & 1000 & 1195 & 1318 & 1171 \\
\hline 4 & 14.7 & 15.0 & 15.5 & 15.1 & 932 & 1134 & 1245 & 1104 \\
\hline 5 & 14.3 & 14.7 & 15.2 & 14.7 & 821 & 1037 & 1152 & 1003 \\
\hline 6 & 14.0 & 14.4 & 14.9 & 14.4 & 728 & 960 & 1076 & 921 \\
\hline 7 & 13.8 & 14.2 & 14.7 & 14.2 & 653 & 886 & 990 & 843 \\
\hline 8 & 13.6 & 14.0 & 14.5 & 14.0 & 566 & 796 & 907 & 756 \\
\hline 9 & 13.4 & 13.8 & 14.2 & 13.8 & 486 & 699 & 797 & 661 \\
\hline 10 & 13.1 & 13.5 & 14.0 & 13.5 & 420 & 614 & 706 & 580 \\
\hline \multirow[t]{2}{*}{ Mean } & 14.5 & 14.8 & 15.2 & 14.8 & 845 & 1041 & 1150 & 1012 \\
\hline & FA & $\mathrm{T}$ & \multicolumn{2}{|c|}{ FA X T } & & FA & $\mathrm{T}$ & FA X T \\
\hline SEd & 0.145 & 0.076 & \multicolumn{2}{|c|}{0.251} & SEd & 13.54 & 7.072 & 23.456 \\
\hline $\mathrm{CD}(0.05)$ & 0.289 & 0.151 & \multicolumn{2}{|c|}{ NS } & $\begin{array}{c}\mathrm{CD}(0.0 \\
5)\end{array}$ & 27.04 & 14.12 & NS \\
\hline
\end{tabular}

Fig.1 Effect of seed treatment on seed germination and seedling growth before forced ageing

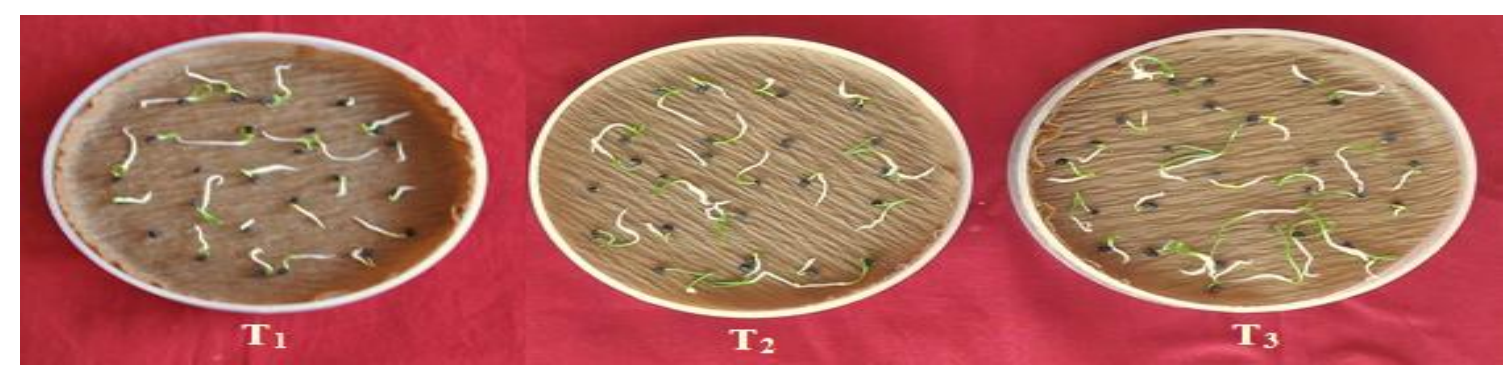

Fig.2 Effect of seed treatment and forced ageing on seed germination and seedling growth at $5^{\text {th }}$ day of forced ageing

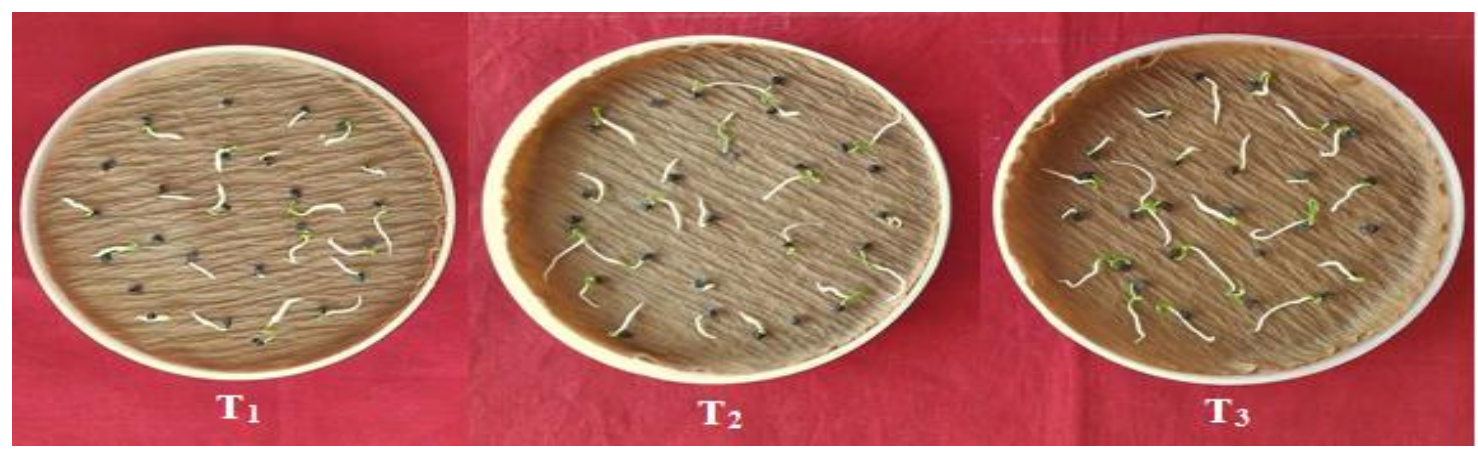


Rice and Ornamental plant (Cyclamen species) treated with foliar application of $\mathrm{GA}_{3}$ improved the germination percentage of resultant seeds (Wang et al., 2019; Cornea-Cipcigan et al., 2020). Seed treatment with $\mathrm{GA}_{3}$ has been resulted in the highest germination percentage in tomato (Balaguera-Lopez, 2009).

Significant influence was observed in root length due to forced ageing. The length of the root was decreased while increasing the period of forced ageing. The longest root of $7.1 \mathrm{~cm}$ was recorded in seeds treated with SCF-II on initiation of force dageing; it was reduced to $6.7 \mathrm{~cm}$ at $3^{\text {rd }}$ day of ageing. Eventually it reached $4.3 \mathrm{~cm}$ on $10^{\text {th }}$ day of forced ageing. Shortest root $(3.1 \mathrm{~cm})$ was recorded in control on $10^{\text {th }}$ day of forced ageing. The same trend was observed in case of shoot length as that of root length. The values ranged between $9.8 \mathrm{~cm}$ and $6.9 \mathrm{~cm}$ for the seeds coated with SCF-II at initial and 10 days of forced ageing. It was recorded minimum $(5.3 \mathrm{~cm})$ for control at $10^{\text {th }}$ day of forced ageing. SCF- I also recorded somewhat higher root and shoot length $(3.8 \mathrm{~cm}$ and 6.6 $\mathrm{cm})$ than the control at the end of forced ageing (Table 2) (Figure 1 \& 2). With increase of forced ageing, there was decrease in seedling shoot and root length. It is line with finding of Hussein,2011 in sunflower.

This result clearly indicates that $\mathrm{GA}_{3}$ and $\mathrm{BR}$ present in the SCF I and II helps in seedling growth even after ageing. Seed treatment with $\mathrm{GA}_{3}$ has been resulted in the highest root length in tomato (Balaguera-Lopez, 2009) and italso has been stimulated the shoot extension growth in eucalypt seedlings (Bachelard, 1968). Brassica juncea seeds pre-soaked with 24-epibrassinolide has been increased the shoot length and root length of seedlings when compared with control (Sharma and Bhardwaj, 2007). BR seed treatment has been enhanced the seedling length in radish (Raghu et. al., 2014). Exogenous Application of Brassinolide has been increased the shoot length and root length in wheat seedlings (ElFeky and Abo-Hamad, 2014).

As, that of germination, root length and shoot length, the dry matter production also significantly influenced by the forced ageing period and negative relationship with each other. The dry matter production was more in seed treated with SCF- II, $16.6 \mathrm{mg}$ seedling ${ }^{-10}$ and $14.0 \mathrm{mg}$ seedling ${ }^{-10}$ at initial and $10^{\text {th }}$ day of forced ageing respectively. SCF-I followed by SCF-II recorded higher DMP than the control at the end of forced ageing (Table 3). It insists that higher seedling length in SCF-I and II leads to higher dry matter production in SCF-I and II. Seed treatment with $\mathrm{GA}_{3}$ has been resulted in the highest dry matter production in tomato (Balaguera-Lopez, 2009). A seed treatment with brassinosteroid has been increased the seedling dry weight in radish and Brassica juncea (Raghu et al., 2014; Sharma and Bhardwaj, 2007).El-Feky and Abo-Hamad, 2014 found that exogenous application of brassinolide enhanced the seedling dry weight in wheat.

The difference due to forced ageing period was significant with respect to vigour index. As all the physiological parameters, the vigour index also decreased while increasing days of forced ageing. The control seeds recorded vigour index of 1350 at initial day of forced ageing, it reduced drastically and reached minimum of 420 on $10^{\text {th }}$ day of forced ageing. Seeds treated with SCF I and II recorded more vigour index (1481 and 1589) at initial day of forced ageing; it reduced to 614 and 706 on $10^{\text {th }}$ day of forced ageing (Table 1).

From the above result, gibberellic acid and brassinosteroid present in the SCF-I and SCFII may involve in seed vigour maintenance during ageing. It indicates that SCF I and II 
delays or reduces the rate of seed deterioration during storage. Seed treatment with gibberellic acid can dramatically increase seedling vigor in rice (Dunand, 1993). Rice and Ornamental plant (Cyclamen species) treated with foliar application of $\mathrm{GA}_{3}$ has been improved the seedling vigor index of resultant seeds (Wang et al., 2019; Cornea-Cipcigan et al., 2020).The film formed around the seed in seeds coated with SCF I and II, it act as a physical barrier, which has been reported to restrict oxygen diffusion to the embryo (Dheerajet al., 2018) and may reduce the catabolic activity or food reserve degradation. Hence, it may be the reason for seed viability and vigour maintenance in onion by SCF I and II during forced ageing. Leelavathi, (2018) who studied the effect of seed coating formulation (contains brassinosteroid) in different crops like maize, black gram and cotton on their storage potential and confirmed that all the seed quality parameters $v i z$, germination, seedling length, dry matter production and vigour index were found to be maximum for the treated seeds than the untreated control.

In conclusion the seeds coated with seed coating formulation I and II maintained the seeds with high seed germination, seedling length, dry matter production and vigour index than the control seeds under forced ageing condition. Seed coating formulation I or II can be used to treat the onion seeds for seed quality enhancement and prolong the self-life.

\section{Acknowledgement}

The corresponding author would like to acknowledge the Department of Seed Science and Technology, Tamil Nadu Agricultural University, Coimbatore, for providing the facilities for the successful completion of the work.

\section{References}

Abdul-Baki, A. A. and Anderson, J. D. 1973. Vigour deterioration of soybean seeds by multiple criteria. Crop Sci. 13: 630-633.

Al-Maskri, A., Khan, M., Khan, I. and Al-Habsi, K. 2003. Effect of accelerated ageing on viability, vigor, lipid peroxidation and solute leakage in carrot (Daucus carota L.) seeds. Int. J. Agric. Biol. 5(4): 580-584.

Bachelard, E. P. 1968. Effects of seed treatments with gibberellic acid on subsequent growth of some eucalypt seedlings. New Phytol. 67, 595-604.

Balaguera-Lopez, H. E., Cardenas-Hernandez, J. F. and Alvarez-Herrera, J. G. 2009. Effect of gibberellic acid $\left(\mathrm{GA}_{3}\right)$ on seed germination and growth of tomato (Solanum lycopersicum L.). Acta Hort. 821: 141-148. DOI: 10.17660/ActaHortic.2009.821.15

Basra, A., Singh, B. and Malik, C. 1994. Amelioration of the effects of ageing in onion seeds by osmotic priming and associated changes in oxidative metabolism. Biol. Plantarum. 36(3): 365.

Basu, R. N. 1995. Seed viability. In: Seed quality, Basra, A.S. (Eds.). Basic mechanisms and agricultural implications, Food Products Press, NEW YORK, U.S.A. 1-44.

Choudhuri, N. and Basu, R. N. 1988.Maintenance of seed vigour and viability in onion (Allium cepa L.). Seed Sci. and Technol. 16:51-61.

Cornea-Cipcigan, M., Pamfil, D., Sisea, C. R. and Margaoan, R. 2020. Gibberellic Acid Can Improve Seed Germination and Ornamental Quality of Selected Cyclamen Species Grown Under Short and Long Days. Agronomy. 10: 516.

Delouche, J. C. and Baskin. C. C. 1973. Accelerated ageing technique for predicting relative storability of seed lots. Seed Sci. and Technol. 1: 427-452.

Demirkaya, M., Dietz, K. J. and Sivritepe, H. O. 2010. Changes in antioxidant enzymes during ageing of onion seeds. Notulae Bot. Hort. Agrobotanici Cluj-Napoca. 38(1): 49.

Dheeraj, M., Dayal, A., Thomas, N. and Ramteke, P. W. 2018.Effects of Seed Pelleting, Polymer Coating and Packaging Materials 
on Seed Quality Characters of Tomato (Lycopersicon esculentum L.)Seeds after Three Months of Ambient Storage. Int. J. Pure App. Biosci. 6 (2): 1511-1518.

Dunand, R. T. 1993. Gibberellic acid seed treatment in rice. LSU Agricultural Experiment Station Reports. 510.

El-Feky, S. S. and Abo-Hamad, S. A. 2014.Effect of Exogenous Application of Brassinolide on Growth and Metabolic Activity of Wheat Seedlings under Normal and Salt Stress Conditions. Ann. Res. and Review in Biol. 4(24): 3687-3698.

Hussein, H. J. 2011. Effect of accelerated aging conditions on viability of sunflower (Helianthus annus L.) seeds. Euphrates J. Agric. Sci. 3(3): 123-136.

ISTA. 2013. International rules for seed testing. switzerland: The International Seed Testing Association

(ISTA). https://www.seedtest.org.

Khan, M. M., Iqbal, M. J., Abbas, M. and Usman, M. 2003. Effect of Ageing on Viability, Vigour and Chromosomal Damage in Pea (Pisum sativum L.) seeds. Pak. J. Agric. Sci. 40: 50-54.

Leelavathi, P. 2018. Evaluation of seed enhancement technologies for improvement in crop growth and productivity. M.Sc. (Ag.) Thesis, Tamil Nadu Agricultural University, Coimbatore.

Leubner-Metzger, G. 2001.Brassinosteroids and gibberellins promote tobacco seed germination by distinct pathways. Planta. 213:758-763.

McDonald, M. B. 1999. Seed deterioration: Physiology, repair and assessment. Seed Sci. and Technol. 27(1): 177-237.

McDonald, M. B. 2004. Orthodox seed deterioration and its repair. In: Handbook of seed Physiology: Applications to agriculture, Benech-Arnold, R. L. and
Sanchez, R.A. (Eds.). Food Products Press, NEW YORK, U.S.A., 273-304.

Merritt, D. J., Senaratna, T., Touchell, D. H., Dixon, K. W. and Sivasithamparam, K. 2003.Seed ageing of four Western Australian species in relation to storage environment and seed antioxidant activity. Seed Sci. Res. 13 (2): 155-165.

Raghu, K., Mahesh, K., Divya Sri, N. and Seeta Ram Rao, S. 2014. Effect of brassinosteroids on seed germination and seedling growth of radish (Raphanus sativus L.) under arsenic toxicity stress. Int. J. Development Res. 4 (9):1929-1933.

Saha, R. R. and Sultana, W. 2008. Influence of seed ageing on growth and yield of soybean. Bangladesh J. Bot. 37(1): 21-26.

Sharma, P. and Bhardwaj, R. 2007. Effect of 24epibrassinolide on seed germination, seedling growth and heavy metal uptake in Brassica juncea. Gen. Appl. plant physiol. 33(1-2): 59-73.

Steber, C. M. and McCourt, P. 2001. A role for brassinosteroids in germination in Arabidopsis. Plant Physiol. 125: 763-769.

Takeuchi, Y., Omigawa, Y., Ogasawara, M., Yoneyama, K., Konnai, M. and Worsham, A. D. 1995. Effects of brassinosteroids on conditioning and germination of clover broomrape (Orobanche minor) seeds. Plant Growth Regulation. 16: 153-160.

Wang, X., Zheng, H., Tang, Q., Mo, W. and Ma, J. 2019. Effects of Gibberellic Acid Application after Anthesis on Seed Vigor of Indica Hybrid Rice (Oryza sativa L.). Agronomy. 9: 861.

Yamaguchi, T., Wakizuka, T., Hirai, K., Fujii, S. and Fujita, A. 1987. Stimulation of germination in aged rice seeds by pretreatment with brassinolide. Proceeding of Plant Growth Regulation Society of America. 14: 26-27.

\section{How to cite this article:}

Sivasakthi' S. and Renugadevi, J. 2020. Seed Storage Potential Assessment in Onion (Allium cepa L. cv. CO (On) 5) through Forced Ageing. Int.J.Curr.Microbiol.App.Sci. 9(09): 31423149. doi: https://doi.org/10.20546/ijcmas.2020.909.388 